\title{
Las Constituciones catalanas de 1706: la cumbre del sistema pactista catalán
}

\author{
Germán Segura García \\ UNED, Madrid

\begin{abstract}
The Catalan Constitutions of 1706: The zenith of the Catalan pact system
\end{abstract}

\begin{abstract}
RESUMEN
En este artículo se estudia el ordenamiento jurídico que supo darse Cataluña en vísperas de la destrucción del sistema pactista que le había vinculado con sus monarcas desde los tiempos medievales. Dejando de lado el análisis de las peculiaridades de dicho sistema, se procederá al examen de su mejor puesta en escena, con el espectro de la guerra civil en ciernes, durante las Cortes de Barcelona de 1705-1706. De esta última reunión de los estamentos catalanes con su monarca surgirían las constituciones de 1706, la ley pactada que quedó malograda por la derrota del bando austracista en la Guerra de Sucesión española.
\end{abstract}

PALABRAS CLAVE: Pactismo / Constituciones / Sucesión española

\section{ABSTRACT}

The article deals with the legal corpus that Catalonia was able to achieve for itself before the destruction of the pact system, which had tied the land with its monarchs from the Middle Ages. Leaving aside the analysis of the peculiarities of this system, we will proceed to the examination of its best staging -the spectre of civil war hanging over Spain- during the Courts of Barcelona 1705-1706. From this last assembly that put together the Catalan states and their king, sprang up the constitutions of 1706, the law ruined due to the defeat of the Austrian faction in the Spanish Succession war.

KEYWORDS:

Pact Theory / Constitutions / Spanish succession

\section{INTRODUCCIÓN}

Una de las consecuencias directas de la Guerra de Sucesión española, en su vertiente de guerra civil, fue la desaparición de la tradición política de algunos territorios de la monarquía hispánica, la reducción definitiva, en aras de una mayor racionalidad, de unos súbditos excesivamente celosos de su ordenamiento jurídi- 
co particular, el ocaso de un sistema contractual que había permitido que las barras de Aragón ondearan sin igual por el Mediterráneo de los tiempos medievales. De entre todos los territorios que antaño pertenecieran a la Corona de Aragón, Cataluña fue la que llevó hasta el límite de la exasperación la defensa de sus libertades, la que defendió hasta el último aliento sus constituciones, quizás con la idea en mente de estar dejando constancia al mundo y a las futuras generaciones del valor, por encima de otras consideraciones, de unas leyes que ellos mismos habían convenido con su monarca y que, con sus virtudes y desaciertos, trataban de adecuarse fielmente a las exigencias de su comunidad.

Pero esta lucha no fue tarea de un día ni se planteó solamente en los muros de aquella Barcelona de 1714, la Barcelona desencajada de la brecha abierta y de los pendones negros gritando al viento «mort o els nostres privilegis conservats» ${ }^{1}$. Los forcejeos con el gobierno de la monarquía, asentado definitivamente en Castilla mediado el siglo XVI, habían llegado a límites insostenibles a lo largo del XVII y, en 1640, una guerra abierta acabó por rematar la falta de sintonía entre unas instituciones que se arrogaron la representación del Principado y un monarca que se les antojaba muy lejano ${ }^{2}$. La contienda civil se superpuso a una guerra internacional en la que estaba en juego la hegemonía de la Casa de Habsburgo y que proseguiría sin solución de continuidad hasta el fin de la centuria.

Durante el reinado del último Austria español, Carlos II, y al tiempo que Francia, liderada por Luis XIV, iba desalojando paulatinamente a los españoles de sus posesiones europeas, la sensibilidad constitucional hacia Cataluña empezó a ser más consecuente con la gravedad de la situación de la monarquía. Este nuevo talante en las relaciones entre el poder real y las instituciones catalanas, después de tantos quebraderos de cabeza, es lo que dio lugar a que algunos autores forjaran un nuevo concepto, neoforalismo, para tratar de bautizar un fenómeno que dista de ser comprendido en toda su complejidad ${ }^{3}$. La teoría más plausible apunta

1 La obra convertida en un clásico sobre este tema es la de BrUGUERA, M.: Historia del memorable sitio y bloqueo de Barcelona y heroica defensa de los fueros y privilegios de Cataluña 1713 y 1714, 2 vols., Fiol y Gros, Barcelona, 1871-1872. Una versión actualizada de los mismos hechos, enmarcando otros aspectos de la guerra, la encontramos en AlbaredA, J.: La Guerra de Successió i l'Onze de Setembre, Editorial Empúries, Barcelona, 2000.

2 Para comprender los antecedentes y las causas del estallido bélico en 1640 permanece insuperada, a mi juicio, la obra de ElLIOT, J. H.: The Revolt of the Catalans. A study of the Decline of Spain (15981640), Cambridge University Press, 1963 (revisada por el autor y traducida en 1977 con el título La rebelión de los catalanes (1598-1640), existe una 5. a edición publicada por Siglo XXI de España Editores, Madrid, 1999).

3 ReglÀ, J.: Els Virreis de Catalunya, Ed. Vicens Vives, Barcelona, 1970, en p.159 fraguó el término y lo expone de la siguiente manera «El pesimismo de Castilla a consecuencia de la derrota militar y de la crisis espiritual de mediados del siglo XVII hizo que su tendencia hegemónica, estrechamente vinculada a la afirmación de la monarquía absoluta, entrase en un periodo de estancamiento, que a la vez condicionaría un fenómeno lógico: el ensayo de una estructura peninsular neoforalista, como representativa de la colaboración de un centro agotado y decadente y una periferia que comenzaba a desarrollarse y que, por contraste con el primero, parecía más floreciente de lo que en realidad era». Por otra parte, ALABRús, R. M.: Felip V i l'opinió dels catalans, Pagès Editors, Lleida, 2001, en p. 37 lo define como «el discurso pragmático de la necesidad de entendimiento entre Cataluña y Madrid, pero siempre bajo el estigma de 
a la debilidad de una monarquía al borde del colapso, atacada en sus propios reductos, como el factor principal que habría facilitado el entendimiento con Cataluña y dejado en suspenso la revisión del sistema pacticta para mejor momento.

Por otro lado y a caballo de la guerra, una incipiente burguesía, bien conectada con la pequeña nobleza catalana, empezaba a adquirir fuerza en el Principado gracias a la neutralización comercial de Francia y a la sustitución de sus productos vitícolas por los catalanes en los mercados del norte de Europa4. La prosperidad de estos mercaderes y, según ellos, la de toda la monarquía residía en sacar mejor partido de las posibilidades que ofrecía el comercio, ya fuera exportando sus excedentes a otras naciones o simplemente dando respuesta a la creciente demanda de productos en sus vastos territorios ${ }^{5}$. Pero para conseguir la aceptación de estas propuestas era necesario algo más que la simple teoría, se imponía la intervención en la política económica de la monarquía.

Colaboración para salvaguardar su ordenamiento jurídico o intervención en el gobierno de la monarquía para hacerla resurgir con sus proyectos económicos, Cataluña parecía decidida a invertir el rumbo de la historia y reclamar para la Corona de Aragón el puesto de prestigio que había ostentado dentro de la monarquía en el momento de la unión dinástica del siglo XV. Además, otro factor de no menor importancia flotaba en el ambiente: Carlos II estaba a punto de morir sin haber sido capaz de asegurar su descendencia. La llamada al trono español de un príncipe extranjero difícilmente se podría saldar sin recurrir al ruido de las armas y, por encima de la decisión testamentaria, los españoles deberían tomar finalmente partido en el conflicto sucesorio. Así fue como, arrastrada, o más bien, atropellada por las circunstancias ${ }^{6}$, Cataluña abrazó decididamente uno de los bandos, ocasión que aprovecharía para saldar definitivamente las cuentas con el gobierno de la monarquía. En su programa de la legislatura inaugurada por el archiduque Carlos, ya Carlos III, los catalanes intentarían redefinir de forma decidida su relación con el

la desconfianza, el recelo y la sospecha», mientras que GARcíA CÁRcEL, R.: Felipe $V$ y los españoles. Plaza \& Janés Editores, Barcelona, 2002, en p. 44 comenta como «el afán de colaboracionismo de la periferia continuó a partir siempre del pragmatismo, el intento de rentabilizar del mejor modo posible una relación de fuerzas favorable por la propia debilidad de la monarquía».

4 Para un estudio detallado de los orígenes mercantiles de algunas familias catalanas ver OLIVA, B.: La Generació de Feliu de la Penya: Burgesia Mercantil i Guerra de Successió entre el Maresme i Barcelona, Edicions de la Universitat de Lleida, Lleida, 2001. En cuanto a las exportaciones vitícolas y el comercio exterior catalán de finales del siglo XVII proponemos el trabajo de VALLS, F.: La Catalunya atlàntica: Aiguardent i teixits a l'arrencada industrial catalana, Eumo Editorial, Vic, 2004.

5 El mejor ideólogo en Cataluña de este renacimiento económico fue el también mercader Narcís FELIU DE LA PEÑA, autor del Fénix de Cataluña. Compendio de sus antiguas grandezas y medios para renovarlas, Rafael Figueró, Barcelona, 1683, donde se señalan las causas de la decadencia del Principado y se proponen diferentes medidas prácticas, muchas de las cuales serían adoptadas parcialmente en las dos últimas reuniones de cortes en Cataluña.

6 Tratar de explicar las causas del alineamiento catalán con el partido del archiduque Carlos resultaría lo suficientemente extenso como para dedicar un artículo entero a este tema. Queden como testimonio de esta problemática los trabajos de AlBAREDA, J.: Els catalans i Felip V, de la conspiració a la revolta (1700-1705), Ediciones Vicens-Vives, Barcelona, 1993; y de ToRRAS, J.M.: La guerra de Successió i els setges de Barcelona (1697-1714), Rafael Dalmau Editor, Barcelona, 1999, que apuntan algunos factores esenciales para comprender la dinámica de los acontecimientos. 
monarca, exigiendo a la vez respeto al ordenamiento jurídico del Principado y mayores responsabilidades en el conjunto de la monarquía ${ }^{7}$.

Nosotros nos detendremos en este punto para analizar algunas de las principales leyes que nacieron de las últimas cortes que vivió la Cataluña del Antiguo Régimen. Tratar de estudiar el marco jurídico en el que se movían las relaciones entre el rey y sus catalanes, la permanente dialéctica pactista, nos ocuparía más espacio del concedido en estas páginas. Nos contentaremos con decir que la ley pactada era sin duda la marca suprema de la libertad de los catalanes y todos ellos, el rey y sus ministros incluidos, estaban sometidos inexcusablemente a ella, resultando ser un poderoso freno a las prácticas absolutistas en auge. Una ley que brotaba de unas cortes donde el monarca en persona y toda la comunidad, dividida en estamentos, se encontraba teóricamente representada y cuyo modelo resuena mucho más a nuestros modernos sistemas democráticos que no cualquier estado absolutista posterior. A dicho modelo de Estado trataremos de acercarnos mediante el estudio de sus constituciones, verdadero testimonio y gloria de la nación que supo instituirlas y esforzarse por defenderlas.

\section{LAS ÚLTIMAS CONSTITUCIONES DE CATALUÑA (1706)}

La toma de Barcelona por el archiduque Carlos en 1705 fue uno de los episodios más significativos de la Guerra de Sucesión, al menos, en su vertiente de guerra civil. Desde el punto de vista estrictamente militar, la Gran Alianza de la Haya, que combatía a los Borbones abiertamente desde mayo de 1702 para elevar al pretendiente austriaco al trono español, había conseguido hacerse con una capital importante en la Península que iba a ser utilizada como principal base de partida para la recuperación de Cataluña primero y del resto de España después ${ }^{8}$. Dejando al margen el aspecto bélico, en este trabajo nos interesa más en concreto el ordenamiento jurídico que surgiría de las Cortes Generales celebradas por el archiduque en Barcelona, las segundas en lo que iba de siglo en Cataluña9.

7 Para ver la actuación y gobierno del archiduque Carlos en Cataluña ver VoLTES, P.: Barcelona durante el gobierno del Archiduque Carlos de Austria (1705 - 1714), 2 vols., Ayuntamiento de Barcelona y C.S.I.C., Barcelona, 1963; y principalmente LEÓN, V.: Entre Austrias y Borbones: El Archiduque Carlos y la monarquía de España. (1700-1714), Editorial Sigilo, Madrid, 1993; de la misma autora, «El reinado del Archiduque Carlos en España: la continuidad de un programa dinástico de gobierno», Manuscrits, 18, (2000), pp. 41-62; y Carlos VI: el emperador que no pudo ser rey de España, Ed. Aguilar, Madrid, 2003.

8 Para el estudio de la Guerra de España ver las obras contemporáneas de CASTELlví, F.: Narraciones históricas, 4 vols., Fundación Francisco Elías de Tejada y Erasmo Pèrcopo, Madrid, 1997-1999; BACALLAR, V. (marqués de San Felipe): Comentarios de la Guerra de España (edición e introducción a cargo de Carlos Seco), BAE, Madrid, 1957; y LóPEZ DE MENDOZA, A. (conde de Robres): Memorias para la historia de las guerras civiles de España. Biblioteca de Cataluña, Manuscritos, n. ${ }^{\circ 151}$. Otros trabajos posteriores sobre el mismo conflicto principalmente desde el punto de vista bélico en VoltES, P.: La Guerra de Sucesión, Editorial Planeta, Barcelona, 1990 y la ya mencionada de ToRRAS, J. M.: La guerra ....

9 No se han de olvidar las Cortes de 1701-1702, presididas por Felipe de Borbón y verdadera referencia de esta segunda reunión. Ver BARTROLí, J.: «La Cort de 1701-1702: un camí truncat». Recerques, 9, (1979), pp. 57-75. Para profundizar en como se desarrollaban las Cortes Generales en Cataluña, ver 
Los catalanes esperaban impacientes la convocatoria de estas nuevas cortes para legitimar los derechos del archiduque como conde de Barcelona y hacerse respetar los privilegios que los anteriores monarcas les habían concedido. Además existía una necesidad añadida ya que la no reunión de cortes — donde en teoría estaba representado el país- implicaba un vacío legal muy incómodo para Cataluña y para el mismo monarca. En las Cortes de Barcelona (1705-1706) las instituciones catalanas intentarían restablecer y aumentar sus prerrogativas, mientras que el nuevo rey, además de afirmar su autoridad, buscaría el apoyo moral de sus súbditos y también, como no, el material, traducido principalmente en el donativo voluntario y en la movilización de las milicias a lo largo y ancho de Catalu$\tilde{n} a^{10}$. La pugna-colaboración entre el monarca y los brazos, esencia del sistema contractual, condujo a la renovación de antiguos privilegios y a la concesión de otros, frutos todos ellos de la voluntad de la nación y del proyecto de futuro que se había planteado.

En este trabajo nos vamos a centrar principalmente en las constituciones que tratan de formalizar las relaciones entre los agentes del monarca y las instituciones del Principado, clarificando el ámbito y alcance de sus cometidos y evitar así interferencias entre ambos poderes ${ }^{11}$. También destacaremos aquellas estipulaciones cuyo objeto era garantizar la legalidad constitucional catalana y los órganos creados para su vigilancia, en especial, el Tribunal de Contrafacciones. Dejaremos en el tintero otros aspectos importantes como los económicos, los militares o los relativos a cada brazo (estamento) de cortes, pero no nos ha sido posible incluirlos en estas líneas sin alargarnos demasiado.

Antes de empezar con los artículos referentes al poder real en Cataluña no podemos dejar de mencionar aunque sea de pasada la primera Constitución de 1706 - también conocida como Ley de exclusión de la Casa de Borbón-y, sin lugar a dudas, el artículo más importante de las Cortes de 1705-1706 desde el

Ferro, V.: El Dret Públic Català. Les Institucions de Catalunya fins al Decret de Nova Planta, Eumo Editorial, Vic, 1987; Peguera, L.: Practica, forma, y estil, de celebrar Corts Generals en Cathalunya, y materias incidents en aquellas (obra escrita a inicios del siglo XVII y reimpresa en 1701 para la celebración de las Cortes de 1701-1702 presididas por Felipe de Borbón, publicada por el Centro de Estudios Políticos y Constitucionales, Madrid, 1998); y COROLEU J. y PeLLA. J.: Las Cortes Catalanas. Estudio jurídico y comparativo de su organización, Imprenta de la Revista de Historia Latina, Barcelona, 1876.

10 Para un estudio de estas Cortes ver el trabajo de GonZáLEZ, M.: «Les Corts Catalanes 1705-1706». L'Avenç, n. ${ }^{\circ} 206$ (1996), pp. 30-33; y el proyecto de tesis doctoral del autor de estas líneas titulado «Las Cortes de Barcelona (1705-1706). El camino sin retorno de la Cataluña austracista», Departamento de Historia Moderna de la UNED. 2003.

11 Llamamos Constituciones a todos los artículos aprobados en las cortes porque así eran conocidos de forma genérica por los catalanes, aunque es bien sabido que de las cortes podían surgir tres tipos de disposiciones: Constituciones, Capítulos de Corte y Actos de Corte. Como explica CAstellví, F.: Narraciones ... vol. 2, p. 36; las Constituciones eran las leyes propuestas por iniciativa del rey a las Cortes Generales y que recibían la aprobación de los brazos; los Capítulos de Corte eran leyes propuestas por las cortes y a las que el rey daba su consentimiento; y, por último, los Actos de Corte son definidos como aquellas «leyes que tienen como finalidad la recta administración y exacción de los decretos que pertenecen a la Diputación del Principado de Cataluña». 
punto de vista político ${ }^{12}$. En resumen, la primera Constitución declaraba nulo el testamento de Carlos II y excluía de la sucesión de la monarquía española a todos los miembros de la Casa de Borbón y a cualquier otro príncipe francés que se creyera con derecho al trono hispano. Los estamentos catalanes ofrecieron fuerte resistencia a la hora de dar su consentimiento a dicha ley y sólo, bajo la presión combinada de los ejércitos borbónicos en Cataluña y de los agentes reales en Barcelona, fue aprobada días antes de la clausura de cortes. A partir de entonces Cataluña ligaba formalmente su futuro a la suerte del monarca austriaco: la posible derrota en la guerra civil vendría acompañada sin duda del desplome del sistema pactista. Pero este temor parecía aún lejano en aquella Barcelona ocupada por las tropas aliadas y convencida de la victoria del archiduque.

A pesar de esta significativa concesión, no se puede suponer que los catalanes acudieran a las cortes como meros convidados de piedra y fueran a aceptar todo lo que el rey pidiera sin más. Todo lo contrario. Como señala Pedro Voltes «las Cortes de 1705-1706 reverdecieron las épocas de mayor gallardía y audacia de las tradicionales catalanas ${ }^{13}$. De hecho, muchas de las constituciones, empezaron por recordar al monarca toda una serie de normas consuetudinarias del Principado que sistemáticamente no se estaban cumpliendo. Por ejemplo, en la Constitución 63 se estipulaba que ningún virrey podía tomar posesión del cargo antes de que el monarca hubiera jurado personalmente en Barcelona observar y guardar las leyes y constituciones de Cataluña ${ }^{14}$. Según la teoría jurídica catalana, a la muerte del monarca, su lugarteniente en el Principado dejaba de tener potestad alguna y se abría un período de vice regia donde la máxima autoridad para la administración de justicia era el general gobernador o su portantveus ${ }^{15}$. Pero la práctica dejaba en en-

12 Un estudio sobre la primera Constitución o Ley de Exclusión en GARCíA SEGURA, G.: «Cataluña contra la monarquía Borbónica. La primera Constitución de las Cortes Catalanas de 1705-1706», Tiempos Modernos $13(2006 / 1)$.

13 Voltes, P.: Barcelona ..., vol. 2, 1963, p. 81.

14 La figura del virrey en la monarquía hispánica se generalizó durante el s. XVI para el gobierno de los reinos de la Corona de Aragón, de Italia y de la América española. La teoría política de la Corona de Aragón consideraba que el virrey era un cargo extraordinario para cubrir la momentánea ausencia del rey y que actuaba por delegación de éste (alter nos) representándole antes sus súbditos. Sin embargo, esta ausencia se hizo regular a partir del reinado de Carlos I, por lo que el virrey, desde la perspectiva de la Corte, pasó de ser un mero lugarteniente a ser un gobernador de mayor porte, en palabras de MoLAS, P.: La Monarquía Española (siglos XVI-XVIII), Historia 16, Madrid, 1990, p. 57. El virrey de Cataluña, llamado oficialmente Llochtinent General, era el más alto magistrado del Principado y solía ocupar el cargo por un trienio, aunque también se podía dar el caso de períodos más largos. Ostentaba al mismo tiempo las funciones de capitán general, lo cual le permitía en algunas ocasiones actuar de forma que tenía prohibida como virrey por las constituciones del país. El cargo se hallaba vinculado a un número restringido de familias de la nobleza, siendo en Cataluña las de Requesens y Cardona quienes ocuparon el puesto con más asiduidad durante los siglos XVI y XVII.

15 La institución de la gobernación general, después de varios altibajos, se estabilizó en 1363 cuando el cargo de gobernador general quedó asociado a la persona del primogénito de la Corona de Aragón. Tenía amplias atribuciones en materia de gobierno y justicia —incluso podía llegar a aplicar la pena capital— aunque el objetivo fundamental del cargo era dar la oportunidad al sucesor de la Corona a familiarizarse con las tareas propias del gobernante, además de entrar en contacto con sus futuros súbditos y acostumbrarlos a reconocer su autoridad. El representante del gobernador general o, según las circunstancias, su sustituto en el Principado era el portantveus de general gobernador. Como ha señalado FERRO, V.: El 
tredicho la norma repetidamente y las instituciones catalanas, impotentes ante la infracción de los agentes reales, acababan en el mejor de los casos protestando por la contrafacción de las leyes y privilegios cometida. Esta constitución saldó definitivamente el problema disponiendo lo que la legalidad catalana había estipulado desde antaño, es decir, que el juramento del nuevo monarca fuera preceptivo para el reconocimiento del nuevo virrey. El Capítulo de Corte 50 completaba esta constitución, estableciendo que a la muerte o ausencia del monarca y del virrey, o al acabar el período de lugartenencia de éste, el general gobernador o su portantveus debería abrir el periodo de vice regia sin tener en cuenta las prórrogas que pudieran ser dispuestas por el virrey. El contenido de este artículo era idéntico a otra norma aprobada en las Cortes de 1702 y que se encontraba ya prevista en las Generales Constituciones, Usos y Costumbres de Cataluña.

Otras disposiciones sobre diferentes oficiales reales intentaban perfeccionar sus cometidos y garantizar la observancia de las leyes. De una forma general, el Cap. 14 anulaba todos los usos y costumbres que, principalmente desde 1599, habían ido o iban en contra de las constituciones y privilegios catalanes ${ }^{16}$. A continuación y como medida previa, el Cap. 88 recordaba que todos los oficiales reales debían jurar las constituciones y los capítulos en el término de un mes a partir de la clausura de cortes, bajo pena de suspensión del oficio. En el Cap. 86, se establecía que los oficiales reales se debían someter a una visita real cada tres años, y en el Cap. 59 se obligaba a los mismos a vivir en la capital de la veguería donde desempeñaban su oficio ${ }^{17}$. Con ello se pretendía prevenir abusos y evitar los gastos de los particulares que debían presentarse ante dichos oficiales para la administración de justicia.

Dret ..., p. 50, la Gobernación General fue una de las instituciones más abstractas e impersonales en la Europa del período. Llegaba a serlo hasta tal punto que su maquinaria seguía funcionando aún cuando su titularidad estuviera vacante. Designado por el rey, ocupaba el cargo de forma permanente y en el caso de que el virrey se hallara impedido o fuera de Cataluña, lo sustituía en el cargo mientras durara su ausencia. Sin embargo, su papel más controvertido era el de sustituir al monarca a su muerte, ya que, desaparecido éste, la potestad del virrey, su alter nos, debía también cesar automáticamente.

16 Las Cortes de Cataluña de 1599 presididas por el rey Felipe III (II de Aragón) son una referencia para los catalanes de este periodo ya que durante todo el siglo XVII no fue posible concluir otras cortes en Cataluña debido a la tensión entre el monarca y las instituciones del Principado. De hecho, hubo dos reuniones frustradas en 1626 y 1632 que dejan patente la falta de sintonía en este periodo y que condujo a la guerra en 1640. Ver ELLIOTT, J.: La rebelión ....

17 Uno de los puntos claves a tener en cuenta en la política de afirmación de la institución monárquica en Cataluña fue la decisión de estructurar el territorio, a lo largo del siglo XIII, en distritos vicariales o veguerías sometidas bajo el control de oficiales reales. La veguería se constituyó en la principal división administrativa y de demarcación de la titularidad real en el Principado. La fortuna de que este sistema de vertebración territorial fuera efectivo y perviviera hasta el siglo XVIII radica en que el monarca supo asumir la realidad de unas regiones definidas espontáneamente, ya fueran condicionadas por la zona de influencia socio-económica de una población o por la legítima jurisdicción que ostentaba en el territorio la nobleza del país. De esta forma, Cataluña se subdividió en 16 veguerías, al frente de las cuales se hallaba un veguer (vicarius), con escasas atribuciones ante la autonomía de la nobleza y de los municipios. El designado para el cargo, que era ejercido durante tres años, era propuesto por el virrey y sancionado por el monarca. El veguer nombraba a su vez a varios oficiales (sotsveguers) para controlar con más eficacia las demarcaciones más extensas de su territorio y a los alcaldes (batlles) de las villas que dependían directamente de la jurisdicción real. 
Continuando con las limitaciones, en el Cap. 18 se ordenaba que los oficiales reales o cualquier otra persona que recibiera rentas del monarca no pudieran ser habilitados para participar en las Cortes Generales o en las Juntas del Brazo militar. Los estamentos habían insistido constantemente en la incompatibilidad de la condición de oficial real y la participación en cortes como miembros de un brazo. En las Cortes de 1702, los brazos presentaron un capítulo que consagraba y precisaba esta incompatibilidad, pero Felipe $\mathrm{V}$ se reservó su asentimiento para una futura reunión. Así quedaron las cosas hasta que la presencia de oficiales reales al inicio de las Cortes de 1706 provocó el primer disentimiento del brazo militar ${ }^{18}$. El monarca, entonces, aceptó que sus agentes abandonaran la reunión y, más tarde, la cuestión quedaría zanjada definitivamente con la aprobación de este capítulo.

Otros artículos hacen referencia, de forma específica, a algunos oficiales reales. Así, la Const. 37 ordenaba al portantveus de general gobernador recorrer el Principado en los seis primeros meses del ejercicio del cargo, prestando en todas las veguerías el habitual juramento de observar sus usos y costumbres. En la Const. 20 se estipulaba que para ocupar el cargo de veguer, además de cumplir el requisito de ser militar o gaudín ${ }^{19}$, se había de ser natural o estar domiciliado en la misma veguería. El nombramiento de los vegueres era potestad del monarca, que escogía de entre los candidatos propuestos por el virrey. Antes de que se aprobara esta constitución, el cargo era ejercido generalmente por un caballero, aunque esta norma no constituía un imperativo legal. Sin embargo, en 1706, el oficio fue reservado en exclusiva al estamento militar.

Con respecto al cargo de canciller del Principado, la Const. 24 estipulaba que la persona que fuera a ocupar dicho cargo debía poseer beneficios en el mismo. La Chancillería Real en Cataluña constituía el principal instrumento jurídico para el ejercicio de la autoridad virreinal ${ }^{20}$. Estaba encabezada por el canciller, que debía ser un clérigo catalán y doctor en derecho canónico o civil. Sus cometidos eran

18 Uno de los mecanismos más característicos de todo el proceso de cortes en Cataluña era el llamado dissentiment. Cualquier asistente podía suscitar, dentro de su brazo, una cuestión relacionada con lo tratado en la corte que justificaba la interrupción de la misma hasta que el punto no fuera resuelto. Los miembros del estamento militar tenían tan alta consideración que bastaba el disentimiento de uno de ellos para que no fuese válido el acuerdo de las Cortes. «Fontanella (jurisconsulto catalán 1576-1649), al tratar de este excesivo privilegio manifiesta que ignora su fundamento, a pesar de las muchas investigaciones que hizo para dar con él, y que ningún caballero se lo supo indicar» (en J. CoRoleu y J. PELLA: Las Cortes ..., pp. 129-130). El brazo, si consideraba que la cuestión planteada era de interés general, hacía suyo el disentimiento y se lo comunicaba a los otros, cesando todos en sus trabajos y paralizando la corte. Si bien el disentimiento podía convertirse en un recurso para obstruir el final feliz de la corte, también y sobretodo representaba un arma formidable en defensa de la legalidad (cfr. FERRO, V.: El Dret ..., p. 219). En el caso de que no se pudiera levantar el disentimiento mediante conversaciones entre las partes implicadas, se procedía a nombrar una comisión formada por miembros de los brazos y por oficiales reales que, después de debatir el asunto, llegaban a una conclusión final. Si el disentimiento estaba provocado por las disputas entre los brazos, se admitía que el rey pudiera proveer por sí solo el litigio.

19 Los gaudins, a pesar de no pertenecer a la nobleza titulada, disfrutaban de las exacciones del estamento militar a causa de su profesión (juristas, teólogos, profesores, doctores...), derecho que no era transmitido a los descendientes.

20 Ferro, V.: El Dret ..., pp. 58-59. 
presidir ordinariamente la Real Audiencia y decidir los contenciosos de jurisdicción entre los tribunales eclesiásticos y seculares ${ }^{21}$. El canciller conservaba el sello real, con el que refrendaba los actos jurídicos emanados por el poder de la monarquía, y cumplía una trascendental función constitucional como administrador legal de la justicia en nombre del rey. El hecho de ser un oficio real ejercido por un eclesiástico venía a garantizar de cierta forma un arbitraje más imparcial de las causas. En cuanto al oficio de vicecanciller de la Corona de Aragón, en las Cortes de 1422, se había aprobado una constitución sobre el mismo en la que se indicaba que el cargo debía ser ejercido por una persona secular, graduado en leyes y nativo y domiciliado en cualquiera de los reinos de la Corona. Posteriormente, cuando el rey Fernando el Católico creó el Consejo Supremo de Aragón, el vicecanciller pasó a convertirse en el presidente del mismo, además de continuar con sus funciones como jefe de la Chancillería Real de la Corona ${ }^{22}$. Con el paso del tiempo, el vicecanciller fue perdiendo el estatus de presidente del Consejo Supremo ${ }^{23}$. Además, el cargo tenía tendencia a recaer sobre un aragonés, hecho que provocó las reclamaciones de los catalanes. Por ello, en el Cap. 47, las Cortes catalanas consiguieron que el oficio fuera concedido, sin dispensa alguna, a los naturales de los reinos de la Corona de Aragón y que se alternara el cargo entre los mismos, empezando por un catalán seguido de un aragonés y un valenciano. En cuanto a la presidencia del Consejo de Aragón, se aprobó que el vicecanciller fuera «lo unich president del dit Supremo Consell de Aragò» 24.

Las Cortes hicieron hincapié, como estamos viendo, en la conveniencia de que algunos oficios reales fueran desempeñados por catalanes, incluso en aque-

21 La Real Audiencia y Real Consejo de Cataluña era el máximo órgano jurisdiccional en materia judicial del Principado. Creada por Fernando el Católico en 1493, adoptaría su forma definitiva en las Cortes de 1599. El monarca o, en su ausencia, el virrey era el presidente natural de la Audiencia. Para la toma de decisiones, consideradas como sentencias reales, el presidente atendía el parecer de un número determinado de doctores, divididos en tres salas, que le asesoraban y daban su parecer sobre la cuestión. Una de las mayores irregularidades de este tribunal supremo, constantemente denunciada por las instituciones locales, fue que fallaba las sentencias de agravios, a pesar de que las faltas, en algunos casos, habían sido cometidas por los mismos oficiales reales de la Audiencia. «La Real Audiencia al superponerse al virrey y al país, acabó apoyando en último extremo al rey y, como verdadero organismo casi senatorial al servicio de la Corona, en ella se encontraba la verdadera gestión judicial y administrativa [...] Estaba condenada a entenderse con el poder real, a topar al final con las constituciones del país y sus instituciones [...]», BelengueR, E.: Cataluña: De la Unión de Coronas a la Unión de Armas, Arco Libros, Madrid, 1996, p. 46.

22 Una de las instituciones fundamentales de la monarquía hispánica para el gobierno de los antiguos reinos de la Corona de Aragón, fue el Consejo de ese mismo nombre creado en 1494 por el rey Fernando el Católico con el fin de servir de consulta y asesoramiento sobre los asuntos de dicha Corona. Establecido en la corte del monarca y, por lo tanto, ausente del marco territorial que debía gestionar, el Consejo de Aragón se fue haciendo, con el paso del tiempo, más dependiente del rey y su capacidad de representación se hizo cada vez más débil. Aún así, se convirtió en un instrumento importante de consulta desde comienzos del siglo XVII y se mantuvo como tribunal supremo de apelación de las sentencias de las Audiencias de Valencia, Mallorca y Cerdeña, y en algunos casos extraordinarios de Cataluña y Aragón.

${ }^{23}$ Desde 1626 a 1646 fueron nombrados presidentes del Consejo de Aragón personas distintas al vicecanciller e incluso, en algunos casos, no naturales de la Corona de Aragón. FerRo, V.: El Dret ..., p. 45.

24 Constituciones de 1706, fol. 105. Facsímil del Archivo de la Corona de Aragón. Editado por Rafael Figueró en Barcelona, 1706. 
llos cargos que no se ejercían propiamente en el Principado. Como principio fundamental, en el Cap. 6 se insistía en que los oficios preeminentes del Principado tenían que ser concedidos a personas «creadas de legitim, y carnal matrimoni ${ }^{25}$, excepto si eran hijos, hermanos o tíos naturales del monarca o de sus sucesores. En aquellas instituciones compuestas por miembros de diferentes naciones, Cataluña intentaba introducir un sistema más racional de representación o reservar plazas en las mismas para sus ciudadanos. Por ejemplo, para ocupar el cargo de protonotario del Consejo Supremo de Aragón, la Const. 11 instauraba un sistema de rotación entre los reinos de la Corona. Tradicionalmente, el cargo había sido prácticamente monopolizado por la familia aragonesa de los Villanueva, hecho que provocó las protestas de los otros reinos ${ }^{26}$. En las Cortes de 1702 ya se establecía un turno entre los mismos y, en las de 1706, se repitió esta última fórmula, iniciándose la rotación del oficio por un catalán: Ramón de Vilana Perlas ${ }^{27}$. También, en el Cap. 10 se establecía que en los consejos reales de Nápoles, Sicilia, Cerdeña, Milán y Mallorca hubiera una plaza fija reservada para los catalanes.

Una de las misiones principales de las Cortes de Cataluña era denunciar y corregir los agravios cometidos contra los particulares o corporaciones del país. La mayoría de estos agravios provenían de los oficiales reales, por lo que las Cortes trataron de definir con claridad sus competencias, recordando al monarca y a sus agentes lo pactado en las leyes del país.

La Const. 22, por ejemplo, se hacía eco de los abusos perpetrados por los oficiales reales que, bajo pretexto de conveniencia para el servicio del rey, abrían las cartas privadas de las personas o corporaciones del Principado. En este artículo se prohibía a todos ellos, virrey incluido, el leer las cartas que venían por estafeta o correo ordinario. Además, se decretaba que el pago del porte se saldaría en adelante en moneda de vellón barcelonesa y no en moneda de plata como venía siendo reclamada ${ }^{28}$. En el Cap. 15 se estipulaba que ningún oficial real o de guerra pudiera exigir impuesto alguno ni a extranjeros ni a naturales del Principado por la extracción de ningún producto, en especial vino y aguardiente, con la salvedad de que no se dirigiera a un país enemigo de la monarquía. Las tasas por importación de cualquier fruto o vitualla tampoco estaban autorizadas. En este mismo sentido, el Cap. 22 ordenaba que tanto los oficiales reales como los de barón o guerra no podían exigir impuesto alguno a los mercaderes o ganaderos que transitaran por el Principado, ya fueran extranjeros o naturales del mismo, y no se les permitía obli-

25 Ibidem, fol. 63.

26 Ferro, V.: El Dret ..., p. 45.

27 Jurista nacido en Oliana (Lleida), fue partidario de primera hora de la causa austracista, siendo por ese motivo arrestado. Tras la toma de Barcelona por el archiduque fue liberado y entró a formar parte de su nuevo gobierno como secretario. Para adentrarse en la figura de este personaje y en sus ideas políticas ver LLUCH, E.: L'alternativa catalana (1700-1714-1740). Ramon de Vilana Perlas i Juan Amor de Soria: teoria i acció austracistes, Eumo Editorial, Vic, 2001.

28 Para evitar suspicacias, el artículo señala igualmente la equivalencia de las monedas: $1 / 2$ real = 12 dineros. 
gar a los paisanos a utilizar sus carretas para transportar granos si no era pagando su justo precio.

Las cuestiones relacionadas con la administración de justicia eran también una fuente permanente de agravios y provocaron gran número de disposiciones que buscaban garantizar la seguridad de los particulares y evitar la corrupción de los jueces.

Los casos regulados en que un ciudadano del Principado podía ser detenido eran cuatro: la detención in flagrante, la captura de mandato por los oficiales superiores, la provisión de captura por un tribunal y los detenidos por el somatén. El Cap. 49 recordaba que cuando el delito había sido cometido en Cataluña y era merecedor de pena corporal, el acusado había de ser encarcelado y debía iniciarse la encuesta criminal. El juez tenía veinticinco días para realizarla, debiendo publicar los resultados de la misma en el plazo de cinco días después de haberla terminado. Estos plazos se extendían (Const. 44) a los capturados, sin previo proceso, de mandato por el virrey, regente de la Real Chancillería y jueces de la Regia Corte. Con el fin de evitar otros abusos, en el Cap. 51 se estipulaba que solamente en los casos de delitos graves y previa provisión de captura verbo facto en el Real Consejo, una persona podía ser obligada a comparecer ante el tribunal que lo solicitaba. Si el acusado no atendía a las llamadas públicas, después de ser acusado sucesivamente de contumacia y rebeldía, era finalmente desterrado, si bien en Cataluña, los únicos casos de sentencias de rebeldía eran los cometidos por crímenes de lesa majestad ${ }^{29}$. El Cap. 1 recordaba, empero, que los oficiales reales no podían obligar a ningún habitante del Principado a presentarse ante ellos sin legítima causa y, en los casos en que procediera ordenarlo, no se podía retener a los mismos más de quince días. Además, en la Const. 46 se prohibía a todos los oficiales reales detener en sus dependencias a cualquier preso. Las Cortes de 1599 ya habían dispuesto que el veguer y el batlle de Barcelona no pudieran tener prisioneros en sus casas. Sin embargo, a lo largo del siglo XVII se experimentaron muchos abusos, por lo que fue necesario volver a confirmar la norma y extenderla a todos los oficiales reales, en especial, al virrey y al portantveus de general gobernador. En la Const. 49 se prohibía igualmente que tanto los oficiales reales como los de barón torturaran a los prisioneros antes de que los mismos pudieran defenderse ante el juez ${ }^{30}$. En cuanto a los testimonios de coartada, se había introducido la práctica de decretar la prisión de las personas que hubieran testificado en contra de lo que ya había probado la encuesta criminal. La Const. 47, con el fin de permitir la defensa de los acusados y no intimidar a los testigos de las causas, fijaba un término de treinta días para interrogar los testimonios de forma que, una vez concluido el plazo, se entendía que habían testificado a favor del acusado.

29 Ferro, V.: El Dret ..., p. 361

30 «[...] posant a alguns impetits de delictes en sitjes, ahont ab poch temps han de morir, ò contraurer graves dolencias corporals [...]». Constituciones de 1706, fol. 39. 
Con respecto a las detenciones que podía realizar la Ciudad de Barcelona, en el Cap. 52 se aprobaba que los consejeros del Consell de Cent barcelonés pudieran arrestar en las prisiones reales a las personas que hubieran delinquido en su jurisdicción. Lo mismo se aplicaba a las detenciones de los barones o señores de vasallos en sus respectivas jurisdicciones. La finalidad de la norma era evitar que el carcelero de las prisiones reales o el mismo virrey pudiera negar la admisión de los presos por no haber sido comunicados sus delitos a algún juez Real. El artículo obligaba a los oficiales reales a admitir y retener a los presos con la simple relación de los hechos proporcionada por los consejeros de la Ciudad. El oficial que custodiara a los presos debería denunciarlos a los jueces reales en el término de dos días y esperar a que se dictara la sentencia antes de proceder con el detenido.

Continuando con las detenciones, con el Cap. 109 se pretendía acotar las casos en que un detenido fuera de la veguería de Barcelona pudiera elevar un recurso por opresión y solicitar la actuación del Real Consejo. Siempre que un detenido era capturado por jueces inferiores, el arma fundamental contra los procedimientos arbitrarios era el recurso a la protección del príncipe. Las deficiencias observadas por el detenido, durante y después del apresamiento, podían ser objeto de una súplica escrita dirigida al virrey solicitando su protección y la intervención del Real Consejo. De esta forma, incluso antes de terminar la causa en el tribunal local, el detenido podía ser trasladado a las cárceles reales de Barcelona. Todas estas disquisiciones provocaban el descontento de los barones, que criticaban la utilización abusiva del recurso por opresión. Así, consideraban especialmente perjudicial el uso de esta potestad real en detrimento de la justicia ordinaria y en casos no del todo justificados ${ }^{31}$. En 1706, el archiduque Carlos se comprometió a desterrar los abusos, pero se reservaba el derecho a atender los recursos en caso de que fuera «grave ò notoria la opressiò»32. Caso particular eran los excesos cometidos con los condenados a galeras. El Cap. 45 recordaba a los capitanes de las galeras reales la obligación de liberar a todos aquellos galeotes condenados a remar por cualquier tribunal catalán y que ya hubieran cumplido el tiempo de la pena. La retención de estos hombres, más allá del tiempo señalado en su condena, era una injusticia inadmisible, por lo que se ordenaba a los oficiales reales que hicieran las gestiones necesarias para que los condenados fueran liberados y dejados en tierra durante las doce horas siguientes al cumplimiento de la pena.

En cuanto a los ministros de justicia y para evitar los casos de corrupción, el Cap. 43 no permitía que los oficiales de la Real Audiencia fueran acompañados por los litigantes a las Salas o que recibieran regalos de los mismos. Igualmente, con el fin de no suscitar las lógicas dudas que podrían surgir al decretarse las causas con mediación de personas parciales a las mismas, la Const. 34 prohibía a los doctores de la Real Audiencia intervenir en las causas de suplicación que ellos mismos hubieran elevado. Por último, la Const. 33 aprobaba imponer la pena de privación

31 Ferro, V.: El Dret ..., pp. 349-354.

32 Constituciones de 1706, fol. 173. 
de oficio a los asesores de la general gobernación que se ausentaran y dejaran de servir personalmente sus cometidos como presidentes de la Audiencia. Desde las Cortes de 1493 se había instituido que en ausencia del primogénito del monarca y del virrey, la Real Audiencia del Principado debía ser presidida por el asesor del portantveus del general gobernador en lugar del canciller y del regente de la chancillería. En estos casos, la Real Audiencia se convertía en Audiencia de la Gobernación y pasaba a enjuiciar las causas civiles y criminales durante el tiempo que duraba la vice regia. Por ello, para no obstaculizar el curso normal de la justicia y exigir el cumplimiento de las obligaciones de cada uno, se recordaba la responsabilidad de los asesores de la gobernación y se les ordenaba la asistencia a los actos del tribunal de la Audiencia.

Continuando con aspectos judiciales, uno de los mayores logros de las cortes del archiduque Carlos fue la creación de un tribunal de garantías constitucionales - Tribunal de Contrafaccions - encargado de resolver de forma consensuada los recursos elevados por anticonstitucionalidad. Hay que tener en cuenta que el sistema pactista se fundaba en el establecimiento de las leyes con el consenso del monarca y de los estamentos, y exigía para su correcto funcionamiento el exacto cumplimiento de lo decretado por las partes implicadas. Nadie, ni siquiera el rey, había de estar por encima de las leyes paccionadas. Ahora bien, el órgano máximo de justicia en el Principado era la Real Audiencia, institución dirigida por oficiales reales y cuya parcialidad no dejaba de ser evidente. Pronto, pues, se hizo necesario algún tipo de procedimiento para salvaguardar lo que hoy llamaríamos principio de legalidad, es decir, que todos los ciudadanos de la comunidad, incluidos el rey y sus oficiales, estuvieran sometidos a las leyes. A estas disposiciones que pretendían instituir un procedimiento eficaz para obligar a la autoridad, llegado el caso, a respetar las leyes de la tierra, se les llamaba «de l'Observança» ${ }^{33}$.

Después de unos tímidos intentos, la constitución de la Observancia vio definitivamente la luz en las Cortes de 1481. Fernando el Católico, en la constitución que empezaba «Poc valdria fer Lleys e Constitucions si no eren per nós e nostres Officials observades [...]", señaló ya la obligatoriedad de observar las leyes y puso en manos de la Real Audiencia las sentencias de agravios que habían de fallarse por actos cometidos por los oficiales reales. Esta constitución significó un gran avance hacia la legalidad, pero daba lugar en ocasiones a interpretaciones divergentes y no acababa de satisfacer a las instituciones catalanas. A menudo los agravios eran cometidos por los doctores de la Audiencia, con connivencia del rey o del virrey, y por la tanto, la imparcialidad de los jueces no podía ser mantenida por mucho tiempo. A pesar de los indudables aciertos del tribunal, estos inconvenientes dieron lugar a un deseo de reforma que chocó con los intereses de algunos estamentos $^{34}$. Cuando Cataluña se incorporó a la monarquía francesa durante la

${ }^{33}$ Ferro, V.: El Dret ..., p. 412.

${ }^{34}$ En las Cortes inconclusas de 1632, el estamento militar no admitió que los barones y sus oficiales estuvieran sujetos a controles constitucionales, Ibidem, p. 418. 
Guerra de Separación (1640-1652) se estipuló que las causas de contrafacción fueran resueltas en un tribunal mixto, formado por oficiales reales y de los brazos. Restituido el Principado a la obediencia de Felipe IV, se volvió al procedimiento previsto por Fernando el Católico en la «Poc valdria». La celebración de las Cortes de 1702 con ocasión de la sucesión de Felipe $V$ a la monarquía hispánica, permitió a los estamentos exponer la problemática de las contrafacciones y proponer la creación de un mecanismo capaz de garantizar de una vez por todas el mantenimiento del orden paccionado. Las disposiciones aprobadas en 1702 fueron recogidas de nuevo en las Cortes de 1706 de forma que, aún introduciendo algunas precisiones e innovaciones apreciables, no añaden ningún concepto importante que no se hubiera tratado en las primeras.

Así, en el Capítulo de Corte 83 se propone la creación de un Tribunal de Contrafacciones con el fin de proceder judicialmente contra los oficiales reales y las instituciones de la monarquía en Cataluña que hubiesen transgredido la legalidad del país o actuado en detrimento de sus habitantes. Al principio del artículo se refieren las razones que obligan a la creación de dicho tribunal: «Com la experiencia hage ensenyát, que la principal causa, entre altres, de la inobservança [de las Leyes], se acostuma originar de haverse comès, y dexat la declaraciò de las contrafaccions, ò contra constitucions en ma dels matexos Doctors de la Real Audiencia, y Real Consell, contra los quals de ordinari se oposan, y acusan las contrafaccions, y axi per lo que reciprocament interessan per rahò de son offici venen á ser lutges, quasi in causa propria, del que resulta notable deservey à Deu nostre Senyor, y á $V$. Magestat, en desconsuelo dels Comuns, y particulars del Principat [... $]^{3{ }^{35}} \mathrm{~A}$ continuación, se señala la composición del tribunal: tres oficiales reales (el canciller, el regent de la cancillería y el doctor más antiguo de la Real Audiencia) y tres miembros de los estamentos (el arzobispo de Tarragona, el presidente del brazo militar y el primer conseller de la Ciudad de Barcelona). También se designan los suplentes de cada uno de ellos para casos de muerte, impedimento o ausencia del titular. Con la nominación de estas seis personas, la Real Audiencia pierde toda potestad en relación con las causas de contrafacciones y debe abandonar estas actividades al tribunal recién creado.

El tribunal había de utilizar para sus reuniones un cuarto de la Casa de la Diputación llamado «de la visita», en adelante, «lo Quarto o Sala del Tribunal de Contrafaccions". Al tomar el cargo, los seis jueces del tribunal debían prestar juramento y oír sentencia de excomunión. Como muestra de gratitud a las personas "que invigilan en la observança de las Lleys de la Patria» ${ }^{36}$, se acuerda pagar por cada reunión del tribunal dos libras de cera blanca y una más para el que presida. Los miembros del tribunal decidían las causas por votación y, en caso de paridad, se extraía a suerte a uno de ellos para dirimirla. Este mecanismo, idéntico al aprobado en las Cortes de 1702, se veía ahora reforzado por otro procedimiento

35 Constituciones de 1706, fol. 128.

36 Ibidem, fol. 132. 
especial de deshacer los empates: la Generalitat, una vez confirmada la igualdad de votos, extraía por procedimiento de insaculación un nuevo juez de entre seis personas, a saber, una por cada uno de los brazos y tres oficiales reales. Una vez exsaculado, el nuevo juez debía resolver la paridad en el espacio de treinta días, siendo remunerado por su trabajo con treinta libras de cera blanca. En el caso de que este nuevo juez recusara el cargo, sería privado por un año de su oficio real o perpetuamente inhabilitado de concurrir a los oficios de la Diputación y de la Ciudad de Barcelona.

El artículo no dejaba lugar a dudas sobre el alcance del tribunal: «en orde á la deguda observança, que deuhen tenir [las Leyes] vingan perço compresos en lo present Capitol, y altres qualsevols disposants sobre las matexas observanças, [...] tots, y qualsevols Officials, tant Reals, com de Barons, y tant los que purgan com los que no purgan Taula, desde el Llochtinent General, fins al mes inferior, $y$ desde el major al menor, Governadors de Plaças, y tots, y qualsevols Officials de Guerra, Auditors General, y demès Assessors [...] ${ }^{37}$ Los oficiales implicados en causas de contrafacciones debían comparecer en un termino de diez días ante el tribunal. La notificación de la convocatoria se hacía con toda una serie de prevenciones tendentes a evitar que el implicado se excusara alegando desconocimiento. Se ponía especial cautela en aquellos recursos que se dirigían contra el virrey, el gobernador general o su portantveus, y se anulaban los trámites engorrosos. En este sentido, para evitar la intromisión de la Real Audiencia, se eximía del requisito de «habilitación» ${ }^{38}$ las citaciones por contrafacción presentadas a dichos oficiales.

El Cap. 84 nos da diversas normas sobre el procedimiento del Tribunal de Contrafacciones. Teniendo en cuenta la diversidad y la urgencia de los de casos a tratar por el tribunal, se aprobaba que los seis jueces de contrafacciones pudieran conceder solamente uno o dos términos probatorios, que no excedieran más de veinte días, con el fin de decretar las causas en el menor plazo posible. También se daban una serie de normas para evitar las ingerencias encaminadas a entorpecer la fase probatoria o a los agentes que en ella debían actuar. Terminadas las dilaciones, los jueces debían declarar las sentencias en el espacio de treinta días, prorrogables a un mes más. En el caso de que se superaran los plazos señalados y la causa no hubiera sido declarada, "sie tinguda per decidida, à favor de la part damnificada, ò que instarà, en lo modo y forma, que serà estát demanàt ${ }^{39}$. Si el veredicto de los jueces conducía a un empate, se designaba un juez a suerte, como estaba estipulado en el capítulo anterior, de forma que si éste tampoco re-

37 Ibidem, fol. 133.

38 «En principi, pertocaba al mateix escrivà de qualificar l'acceptabilidad del document presentat [habilitarlo]; els escrivants començaren, però, a consultar l'Audiència en cas de dubte; més tard, la part interessada donava l'escrit al president d'una de les sales, el qual la llegia i la tornava al peticionari un cop suprimides las expressions inconvenients que hi poguessin haver, a fi que la poguès presentar oficialment; a partir de determinada data, aquesta habilitació era signada pel president en qüestió...», FERRO, V.: El Dret ..., p. 386.

39 Constituciones 1706, fol. 139. 
solvía en diez días, la sentencia era declarada a favor de la parte que instaba la contrafacción. En cuanto a las contrafacciones pendientes, al ser muy difícil poder declararlas en el término de cuatro meses, se aprobaba prorrogar el dictamen hasta un máximo de un año, contado desde el cierre de cortes. Por último, se prohibía a los diputados consultar a los doctores de la Real Audiencia por los hechos de contrafacciones o por cualquier otro negocio. Para buscar consejo jurídico podían tan sólo consultar «los Advocats de major credit, zel, rectitud, y constancia de esta Ciutat de Barcelona» ${ }^{40}$.

Se ha de recordar que las causas de contrafacción comportaban, por un lado, el juicio sobre la responsabilidad del oficial acusado y, por el otro, la determinación de la licitud o no del acto impugnado y la consecuente indemnización del agraviado. El Cap. 85 dejaba claro que «si la Contrafacció será feta ab dol, mala fe, scientment, ò culpa latta, puga, y dega lo contrafactor [...] esser condempnàt á la anullaciò, cassaciò, revocaciò, y plena reintegraciò de tot lo contrafet, y obrát, y à la refecciò de tots los danys extrinsechs, è intrinsechs, $y$ en son cas de fruyts, è interessos, à favor de la part leza, y en las demès penas, per dret comu, y municipal imposadas á tals contrafactors» ${ }^{41}$.

Las disposiciones sobre el Tribunal de Contrafacciones permiten apreciar el esfuerzo de una nación por delimitar con claridad las responsabilidades de sus miembros y de la autoridad pública. Las instituciones catalanas, dentro de la coherencia del sistema pactista, se enfrentaron con entereza a este problema hasta conseguir, en vísperas de la Guerra de Sucesión, una solución tan coherente y sistemática que, como señala Ferro ${ }^{42}$, todavía hoy puede servir de ejemplo e inspiración.

Una vez disueltas las cortes, los Comunes de Cataluña - Junta del Brazo militar, Diputación del General y Ciudad de Barcelona- debían representar al país ante el monarca y se encargaban de velar por el cumplimiento de lo pactado. El papel de estas tres instituciones era, por lo tanto, de vital importancia para la estabilidad política del país. A la hora de enfrentarse con algún problema, los Comunes trataban por separado la cuestión y si finalmente disentían en la forma de resolverlo - caso bastante frecuente- se creaban comisiones especiales con representación de todos ellos para tratar de llegar a un acuerdo consensuado. Para evitar suspicacias de los agentes reales, en la Const. 18 se autorizó que los tres Comunes, o dos de ellos, pudieran tener libremente y por medio de personas elegidas las conferencias que considerasen necesarias para discurrir lo que les pa-

40 Ibidem, fol. 141.

41 Ibidem, fols. 142-143.

42 «Amb prou feines ens veiem amb cor d'afegir un comentari sobre aquests darrers fruits d'una tradició institucional que havia de morir vuit anys després per no tornar a renéixer mai més. Qui conegui la història i els resultats de la llarga i complicada lluita de la justícia contra el voluntarisme modern per enquadrar l'administraciò dins els límits del dret, sotmetre-la a uns recursos judicials i constitucionals i exigirli responsabilitats, podrà valorar el nostre vell procediment contenciós administratiu, el qual [...] era un producte inconfusiblement autòcton, orfe de l'homologació de models exteriors», FERRO, V.: El Dret ..., p. 424. 
reciera en beneficio de sus corporaciones. Del mismo modo, la Const. 64 prohibía a los oficiales reales interrogar a cualquier individuo sobre lo tratado en las reuniones de los Comunes del Principado. El objetivo era evitar una práctica que se había puesto en evidencia durante los últimos virreinatos y que atentaba contra el juramento que habían contraído los Comunes de guardar el secreto de sus reuniones ${ }^{43}$. Además de insistirse en la contrafacción que cometía el agente real al inquirir sobre dichos asuntos, se imponía también la pena de privación de oficio y desinsaculación a los comunes que revelaran el contenido de cualquier negocio tratado por los mismos.

Otra prerrogativa característica de los Comunes era la posibilidad de enviar embajadas al monarca para exponer sus problemas o para pedir su consejo, facultad que muchas veces era denegada por los ministros reales sin motivo aparente. La Const. 60 trataba de poner fin a este agravio, ya que prohibía a cualquier persona, especialmente a los oficiales reales, impedir que los enviados de las instituciones del Principado pudieran llevar a buen término las embajadas al monarca. Esta había sido una de las causas principales de las disputas entre el poder real y las instituciones locales ya que, siendo "una de las nostras majors soberanias" ${ }^{44}$, los embajadores no cumplían en muchas ocasiones su objetivo de hacer llegar las representaciones al rey e incluso podían llegar a ser detenidos. En esta constitución se confirma el derecho a representación de las instituciones catalanas y se concede igualmente a la Real Audiencia la potestad de elevar consultas al monarca independientemente del virrey o de otro ministro real. También, en la Const. 17, el monarca confirmó todos los privilegios y libertades de los Comunes y particulares de los tres estamentos, así como las prerrogativas y forma de celebrar cortes en el Principado. Para vigilar el cumplimiento de lo pactado, en el Cap. 87 se aprobó que los diputados del General, teniendo noticias de que se había cometido una contrafacción, estuvieran obligados a declararla en el término de tres días y se les autorizaba a gastar el dinero que estimaran oportuno para la defensa de las leyes.

Con respecto a las funciones de la Diputación del General, se intentó definir cual era su papel cuando las cortes estaban convocadas ${ }^{45}$. Así, en el Cap. 2 se re-

43 «Y com [...] de poch temps à esta part, se hage experimentàt, la captura de algunas personas, que havian ocupàt lo carrech Consular de la Ciutat de Barcelona, y que componian lo Consell de Cent, inquirint contra de uns per negocis, y fets proposàts, y votàts en dit Consell, y volent compellir als altres à testificar en ditas inquisicions, y condemnantlos desprès de llarga detenciò de presò, a la pena de desterro, y altres [...]». Constituciones de 1706, fol. 58.

44 Constituciones de 1706, fol. 45-46.

45 El origen de la Diputación del General o Generalitat hay que buscarlo en las comisiones nombradas en cortes para proceder a recaudar el donativo concedido al monarca. Más tarde, en 1359, la actividad política exterior de los monarcas aragoneses obligó a dar continuidad a este tipo de comisiones, que se consolidaron con la creación de la Diputación. Su composición sufrió varias modificaciones, fijándose en el siglo XV con la designación trienal de tres diputados y tres oidores de cuentas por estamento. En 1493, Fernando el Católico estableció para el nombramiento de diputados el sistema de insaculación y extracción a suerte. Con esta medida el monarca se proponía combatir la oligarquía local que pretendía acaparar los cargos y, bajo el amparo de la Diputación, oponerse a su autoridad. Para su 
cordaba que la jurisdicción de los diputados del General de Cataluña debía cesar al congregarse la Corte General. La única actividad que se autorizaba a los diputados era la de continuar con la exacción de los derechos de la Generalitat y otros dependientes de la misma. Según la teoría política, en la Corte General estaba presente la «república» o «cuerpo místico» de Cataluña y los brazos eran el General de Cataluña en plenitud, por lo que estos podían reasumir las funciones que en los periodos entre cortes desarrollaba la Diputación. Sin embargo, la relación entre diputados y brazos, una vez reunidas las cortes, no estuvo exenta de conflictos. En 1632, a causa del derecho que tenían los estamentos de insacular candidatos en las bolsas de la Diputación, se puso en entredicho la subordinación de los diputados con respecto a los Brazos y el conflicto no se resolvió hasta entrado el siglo XVIII ${ }^{46}$. En las Cortes de 1702 se dispuso una constitución que saldó la polémica al recordar que los diputados eran meros administradores de la Corte y que su jurisdicción debía cesar cuando ésta estaba congregada, doctrina que fue renovada en las Cortes de 1706.

Para terminar con este breve repaso a las constituciones no podemos dejar de mencionar el donativo ofrecido por las cortes al monarca. De hecho, uno de los motivos principales que tenía el rey para convocar cortes en Cataluña era la obtención del donativo ya que, para subvencionar los gastos extraordinarios de la monarquía, no había medio de imponer nuevos impuestos a los catalanes ni de conseguir cualquier otro subsidio del país sin la aprobación de los estamentos allí reunidos ${ }^{47}$. El donativo era considerado por los catalanes como un sacrificio libremente consentido y se condicionaba a la satisfacción de los agravios presentados en la legislatura ${ }^{48}$. El concepto que los catalanes tenían de este subsidio e incluso

funcionamiento, la Diputación se alimentó de una serie de impuestos, llamados drets del General, que gravaban la entrada y salida de productos en el Principado o la compra-venta de ciertos artículos. La naturaleza estrictamente económica de la institución, justificativa en último término de su creación, fue dando paso a otro tipo de atribuciones políticas y de representación que acabaron por encauzar la oposición del país frente a la monarquía. Precisamente, en 1652, Felipe IV se reservaría las insaculaciones de la Diputación tras el protagonismo de la institución durante la Revuelta Catalana, situación que permaneció hasta el año 1706 en el que, al menos nominalmente, el archiduque Carlos renunció a tal regalía.

46 Ferro, V.: El Dret ..., p. 224.

47 El donativo se otorgaba por mera y franca liberalidad, «fundábanse para ello las Cortes en los privilegios concedidos por Alfonso II el día 7 de Noviembre de 1289, y Jaime Il el día 23 de Marzo de 1291 [...] Por otra parte, en la Constitución Atorguem, volem, dictada por Pedro II en las Cortes de Barcelona de 1283, y la titulada Vectigals, de Felipe II en las Cortes de Monzón de 1553, se estableció también el principio de que el Rey no podía imponer nuevos tributos sin el consentimiento y aprobación de la asamblea», en Coroleu, J. y PelLA, J.: Las Cortes ..., pp.114-115.

48 «La dita Cort, ò los tres Braços de aquella, seguint la propria naturalesa, è innata fidelitat dels Cathalans, imitant à sos Predecessors, que may han faltát al servey de sos Princeps, y Senyors Predecessors de V. Magestat, de immortal memoria, no perque en aço sien, ò pugan esser obligats, ò estrets en manera alguna, ni per esguart, ò respecte, que altres Regnes à V. Mag. sotsmesos, li hagen fetas offertas, serveys, ò donatius, com los habitants en dit Principat sien Pobles franchs, y lliberts de tota exacciò, é imposiciò forçosa, ab expressa protesta, que per lo present acte, y cosas en aquell contengudas, en esdevenidor, no pugan esser tretas en consequencia, ni pugan esser obligats en general, ni en particular, mes del que voluntariament se obligan: La dita present Cort, ò los tres Braços de aquella de sa propria, y mera voluntat, per las causas sobreditas, ab las reservacions, y salvetats en semblants actes acostumadas, las quals volan haver en la present per repetidas, è insertadas, y ab las condicions, y mo- 
el lenguaje utilizado en el ofrecimiento a su monarca es una muestra más del talante pactista propio de la nación, del sentimiento de libertad-legalidad que recorría, como la sangre, el cuerpo de la comunidad política. El rey, asombrado quizás por la insolencia de tal ofrecimiento pero apremiado siempre por las circunstancias, debía transigir a regañadientes con la forma y aceptar sin más contemplaciones el donativo concedido generosamente por sus súbditos. Una vez regularizado éste, el rey otorgaba las Constituciones y Capítulos suplicados por los estamentos y daba licencia a sus miembros para retirarse. Con este acto final se daban por clausuradas las Cortes de Cataluña «tan famosas por su acrisolada lealtad y su inquebrantable entereza, y en las cuales se hallaban comprendidas todas las glorias y todas las fuerzas vivas de la Nación ${ }^{49}$.

\section{CONCLUSIONES}

En el encabezado de este trabajo hemos titulado las Constituciones de 1706 como la cumbre del sistema pactista catalán. La historiografía catalana suele señalar el apogeo de las Cortes entre los reinados de Pedro el Ceremonioso (1336) y del primer Trastámara, Fernando de Antequera (1413), debido al hecho de que el poder creciente del monarca todavía se mantuvo durante este periodo fuertemente mediatizado por la resistencia de los estamentos, principalmente por la nobleza. En estas condiciones, las leyes tenían tendencia a favorecer a los privilegiados, convirtiéndose muchas veces en una barrera que evitaba la intromisión de un monarca más preocupado en las glorias militares en Ultramar que en la búsqueda de mayor justicia para sus súbditos. La condescendencia del poder real, en un periodo de expansión económica y militar, favoreció el apoyo nobiliario y condujo a Cataluña a convertirse en la reina del Mediterráneo y a sus ejércitos en el temor de Italia y Grecia. Es por ello que algunos nostálgicos resaltan este periodo de la historia como la verdadera edad de oro de Cataluña y sólo hallan en ella aciertos.

Pero Cataluña, aunque forjada durante los tiempos medievales, no puede ser reducida a este periodo, incluso diríamos que su espíritu brilló con más fuerza en el siglo XVIII como nunca antes jamás. Porque cuando los vientos soplan a favor es fácil mantener el rumbo hacia el fin del mundo. Pero cuando la tempestad arrecia, cuando el mar amenaza con echar a pique la nave, se hace difícil permanecer en el puente y sujetar el timón. Y la tempestad llegó para Cataluña en el siglo XVII e inicios del XVIII. Su sociedad, ya castigada durante el siglo XIV, acabó de agrietarse durante la Guerra Civil catalana (1462-1472) y, posteriormente, tras parchear sus heridas, se conformó con una dorada mediocridad durante el siglo XVI.

dificacions devall contengudas, y no sens ellas, per aquesta vegada tantsolament, de llur mera liberalitat, y espontanea voluntat, offerexen, y fan donatiu graciòs à $V$. Magestat de dos milions, moneda corrent, en la sua Ciutat de Barcelona, pagadoras per los Deputats del present Principat, à V. Magestat [...]", Constituciones de 1706, fols. 178-179.

49 Coroleu, J. y Pella, J.: Las Cortes ..., p. 133. 
La rebelión catalana de 1640 fue el precio pagado por la timidez de los catalanes en un periodo de expansión conjunta de todos los reinos españoles. Cuando Cataluña quiso reclamar un puesto en el entramado de la Monarquía se dio cuenta que Castilla hacía tiempo que había copado cualquier acceso a un monarca cada vez más castellanizado. Por si esto fuera poco, el signo de los tiempos tampoco favorecía el sistema constitucional catalán. El poder real estaba en un proceso de revitalización ideológica que condujo a los monarcas a eliminar trabas a su gestión y a ejercer el mando de forma más efectiva sobre todos sus territorios. Y fue en estas condiciones, con el constitucionalismo perdiendo terreno en la Europa continental, cuando los catalanes, aprovechando la entronización de un monarca extranjero, quisieron apuntalar el sistema contractual y renovar sus privilegios y compromisos con la monarquía. Desde este punto de vista podemos considerar las Constituciones de 1706 como la cumbre del sistema pactista catalán. El conocimiento de la mecánica de las Cortes Generales en Cataluña nos reafirma en esta idea ya que, en teoría, la última reunión suele mejorar las precedentes, perfeccionando las leyes del país y adaptándolas a la altura de los tiempos.

Las Constituciones de 1706 son la herencia de aquella generación de catalanes, una generación que tuvo la oportunidad de participar en dos reuniones de cortes casi consecutivas, cosa que sus padres no habían ni podido soñar décadas antes. Quizás por ello, los presentes tenían un sentimiento extra de responsabilidad que les impulsó a hacer las cosas mejor que nunca y buscar sinceramente la resolución de los problemas. Además, el monarca no iba a agravar más su situación con la amenaza de guerra en el horizonte. Las Cortes de 1701-1702 sirvieron de entrenamiento a unos catalanes que habían recurrido a los libros de los juristas y a las actas de las pasadas reuniones para conocer el funcionamiento de sus cortes. Tres años más tarde, las Cortes de 1705-1706 les permitieron perfeccionar el ordenamiento surgido en la anterior reunión, cuyas estipulaciones fueron renovadas con ligeras modificaciones.

Así, el corpus jurídico surgido de esta última reunión constituye el testamento final de la Cataluña del Antiguo Régimen. Sus disposiciones nos permiten conocer de cerca los problemas de esa sociedad catalana de inicios del siglo XVIII, sus aspiraciones y sus soluciones para permitir una mejor gobernabilidad del país. Pero, sobretodo, las Constituciones de 1706 buscaron delimitar con claridad las responsabilidades del poder real y de las instituciones de la tierra para lograr el tan ansiado bien común. El principio de legalidad, el Tribunal de Contrafacciones precedente, salvando las distancias, del Tribunal Constitucional-, el control en la gestión de los agentes reales e institucionales...; todas estas medidas nos son familiares en los actuales sistemas democráticos y nos permiten apreciar aún más la tarea realizada por estas cortes para garantizar la constitucionalidad frente a la arbitrariedad y la injusticia. Porque lo justo, ahora como entonces, era lo estipulado en la ley pactada y los catalanes se aferraron siempre a ella conscientes de que era el baluarte de su libertad. Para ellos, decir pàtria era como decir constitucions y el amor a la patria era entendido como el amor por esas leyes que ellos 
mismos se habían dado en concierto con su monarca. El solo rumor de que alguien podía atentar contra ellas bastaba para exacerbar el temple de unos catalanes siempre dispuestos a defenderlas hasta el último aliento. Por eso, cuando la tempestad llegó, los catalanes optaron por ceñirse al timón y soportar el embate de un mar furioso, hasta que finalmente la castigada nave se fue a pique y con ella las leyes que le habían permitido navegar libremente por los mares de la historia.

El estudio de esas leyes es el estudio del espíritu de Cataluña y también, como no, de España. Porque las Constituciones de 1706 no son únicamente patrimonio de los catalanes sino orgullo de todos los españoles de hoy y de mañana que, al mirar atrás, pueden contemplar como sus antepasados fueron capaces, como tantas otras veces, de anteponer la muerte a sus vidas por un sueño incierto llamado libertad. 